\title{
Multi-Body Modeling and Simulation for the Mars Phoenix Lander Entry, Descent and Landing
}

\author{
Eric M. Queen ${ }^{1}$, Jill L. Prince ${ }^{2}$ and Prasun N. Desai ${ }^{3}$ \\ NASA Langley Research Center, Hampton, VA, 23681
}

\begin{abstract}
A multi-body flight simulation for the Phoenix Mars Lander has been developed that includes high fidelity six degree-of-freedom rigid-body models for the parachute and lander system. The simulation provides attitude and rate history predictions of all bodies throughout the flight, as well as loads on each of the connecting lines. In so doing, a realistic behavior of the descending parachute/lander system dynamics can be simulated that allows assessment of the Phoenix descent performance and identification of potential sensitivities for landing. This simulation provides a complete end-to-end capability of modeling the entire entry, descent, and landing sequence for the mission. Time histories of the parachute and lander aerodynamic angles are presented. The response of the lander system to various wind models and wind shears is shown to be acceptable. Monte Carlo simulation results are also presented.
\end{abstract}

$\begin{array}{ll} & \\ \text { AoA } & =\text { Angle of Attack } \\ \text { AGL } & =\text { Above Ground Level } \\ \text { CG } & =\text { Center of gravity } \\ \mathrm{C}_{\mathrm{D}} & =\text { Drag Force Coefficient } \\ \mathrm{C}_{\mathrm{N}} & =\text { Normal Force Coefficient } \\ \mathrm{C}_{\mathrm{M}} & =\text { Pitching Moment Coefficient } \\ \mathrm{C}_{\mathrm{T}} & =\text { Tangential Force Coefficient } \\ \text { DOF } & =\text { Degrees of Freedom } \\ \mathrm{E} & =\text { Atmospheric Entry Time } \\ \text { EDL } & =\text { Entry, Descent and Landing } \\ \text { HDA } & =\text { Hazard Detection and Avoidance } \\ \text { Ixx, Iyy, Izz } & =\text { Moments of Inertia about X, Y, Z axes } \\ \text { Ixy, Ixz, Iyz } & =\text { Products of Inertia in X-Y, X-Z, and Y-Z planes } \\ \text { L } & =\text { Spacecraft Landing Time } \\ \text { LADT } & =\text { Low Altitude Drop Test } \\ \text { LES } & =\text { Large Eddy Simulation } \\ \text { M } & =\text { Mach Number } \\ \text { MER } & =\text { Mars Exploration Rover } \\ \text { PEDLAM } & =\text { Phoenix EDL Atmospheric Model } \\ \text { RSS } & =\text { Root Sum of Squares } \\ \text { TKE } & =\text { Turbulent Kinetic Energy } \\ \mathrm{V}_{\mathrm{h}} & =\text { horizontal velocity } \\ \mathrm{V}_{\mathrm{v}} & =\text { vertical velocity } \\ \gamma & =\text { inertial flight path angle } \\ & \end{array}$

${ }^{1}$ Senior Aerospace Engineer, Atmospheric Flight \& Entry Systems Branch, MS 489, eric.m.queen@nasa.gov, AIAA Member.

${ }^{2}$ Aerospace Engineer, Atmospheric Flight \& Entry Systems Branch, MS 489, jill.l.prince@nasa.gov, AIAA Member.

${ }^{3}$ Senior Aerospace Engineer, Atmospheric Flight \& Entry Systems Branch, MS 489, prasun.n.desai@nasa.gov, AIAA Associate Fellow. 


\section{Introduction}

A multi-body flight simulation for the Phoenix Mars Lander has been developed that includes a high fidelity model for the parachute. During final descent, the Phoenix Lander relied heavily on its onboard radar to measure distance to the ground and vertical and horizontal velocities. The radar was sensitive to rotation rates of the antennae and was susceptible to a reduction in performance for angular rates greater than $100 \mathrm{deg} / \mathrm{s}$. Use of the radar system places additional emphasis on accurate modeling of the parachute dynamics because the system depends critically on the exact orientation of the lander relative to the surface. To accurately model the dynamics of this system requires a high fidelity end-to-end simulation of the entire entry, descent and landing (EDL) sequence. Flight simulation of a vehicle with parachutes is mathematically complicated and not easily characterized using point-mass or single rigid body approaches. It involves multiple bodies, some of which are very flexible, flying in close proximity with significant interaction effects. Because the bodies fly so close to one another, the flowfield around each vehicle has an aerodynamic effect on the others. There are also direct, physical connections via lines. These lines exert a tension force that is a function of both the relative positions and the relative velocities of the connected bodies.

This multi-body simulation of flight under a parachute was incorporated into a larger simulation of the entire entry, descent and landing (EDL) sequence. In the current work, the parachute, from the riser confluence point back, is treated as a rigid body, with the interaction forces between the parachute and other rigid bodies included. A similar treatment was used to simulate Viking drop-test flights ${ }^{1}$, as well as the Mars Exploration Rover (MER) entry trajectory. Detailed modeling of the dynamic aero-structural interaction of a flexible body such as a parachute is impractical in a full entry simulation. By treating the parachute as a rigid body, it is possible to create an end-to-end simulation from the last trajectory correction maneuver before atmospheric entry to touchdown. This simulation provides a realistic model of the descending parachute/lander system dynamics. In particular, position, attitudes and attitude rates are simulated and used to drive high fidelity models of the onboard radar and flight software. This exercise of the onboard system provides a method to assess system performance and to identify potential sensitivities for landing. Other issues such as recontact with jettisoned elements (heatshield, backshell, parachute mortar covers, etc.), design of parachute and attachment points, and desirable line properties can also be assessed using this simulation.

\section{Entry, Descent and Landing Sequence}

The Phoenix mission performed a direct entry at Mars. The vehicle entered the Martian atmosphere then decreased velocity via atmospheric drag until a Mars heritage disk-gap-band parachute was deployed. The entry, descent and landing sequence of events is shown in Fig. 1.

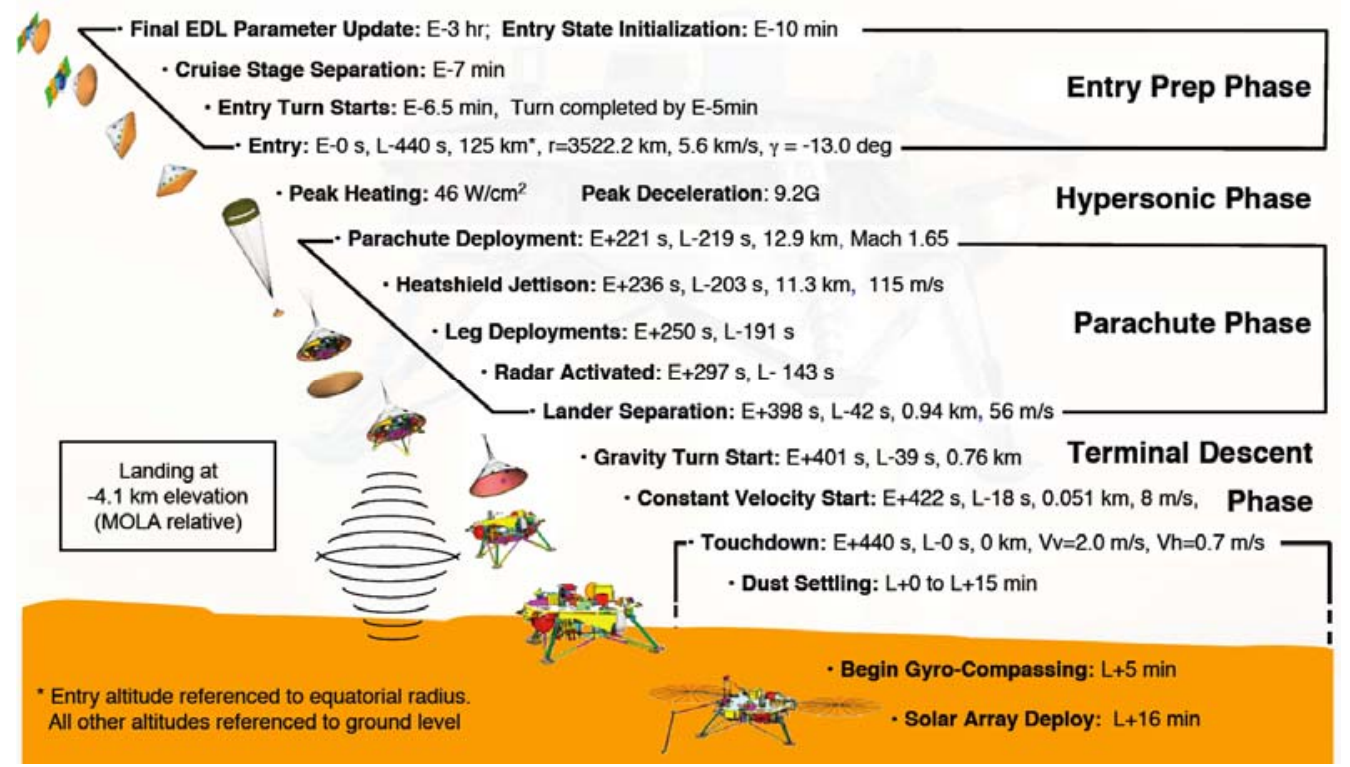

Figure 1. Phoenix EDL sequence of events.

American Institute of Aeronautics and Astronautics 092407 
The reference mission begins when the onboard entry state is initialized at E-10 min prior to atmospheric entry. Atmospheric entry is assumed to occur at a radius of $3522.2 \mathrm{~km}$ (radial altitude of $125 \mathrm{~km}$ ). The entry inertial velocity is $5.6 \mathrm{~km} / \mathrm{s}$ and the inertial flight path angle is $-13.0 \mathrm{deg}$. When the vehicle is slowed to Mach 1.65 (approximately $370 \mathrm{~m} / \mathrm{s}$ ), the parachute is ejected from the back of the spacecraft by a mortar. The mortar is sized to have an initial separation velocity relative to the spacecraft of $37.92 \mathrm{~m} / \mathrm{s}$. The parachute is packed in a bag (assumed massless for modeling analysis) until the lines connecting the parachute to the vehicle become taut, at which point, the bag is discarded and the parachute begins to inflate.

Following deployment of the parachute, the heatshield is jettisioned and the lander legs are deployed. Once the lander legs are deployed, the radar is activated. The parachute/lander combination descends until lander separation, which occurs at a nominal altitude of $940 \mathrm{~m}$. This separation altitude is determined by the onboard flight software, after which the lander performs a tip-up maneuver and then descends to the surface under power of its main descent engines.

The Phoenix lander was actively controlled but unguided during its entry, descent and landing. The control system was tuned to minimize thruster firings prior to the deployment of the parachute. All of the critical events of the EDL phases were triggered by onboard flight controls. Reference 2 provides an overview on the development and evolution of the EDL sequence.

This multi-body simulation modeled all the EDL phases of Phoenix: entry preparation, hypersonic, parachute, and terminal descent, including the onboard sequencing. Reference 3 provides a detailed description of many of the models incorporated into this simulation. However, the simulation described in Ref. 3 modeled the capsule and parachute as a single, rigid body, while the simulation described in this paper models the capsule and parachute as separate bodies (i.e., a multi-body simulation). Consequently, actual two-body capsule/parachute dynamic behavior is obtained allowing a more realistic determination of the performance characteristics of the radar for landing. While both the single body and multi-body simulations were used throughout design and operations of the mission, the single body was primarily used during the final days leading to Mars entry due to its faster run time. Performance of the radar was of great concern, since successful landing was so reliant on successful operation of the radar. The geometry of the lander with a supersonic parachute deployed is shown in Fig. 2. 


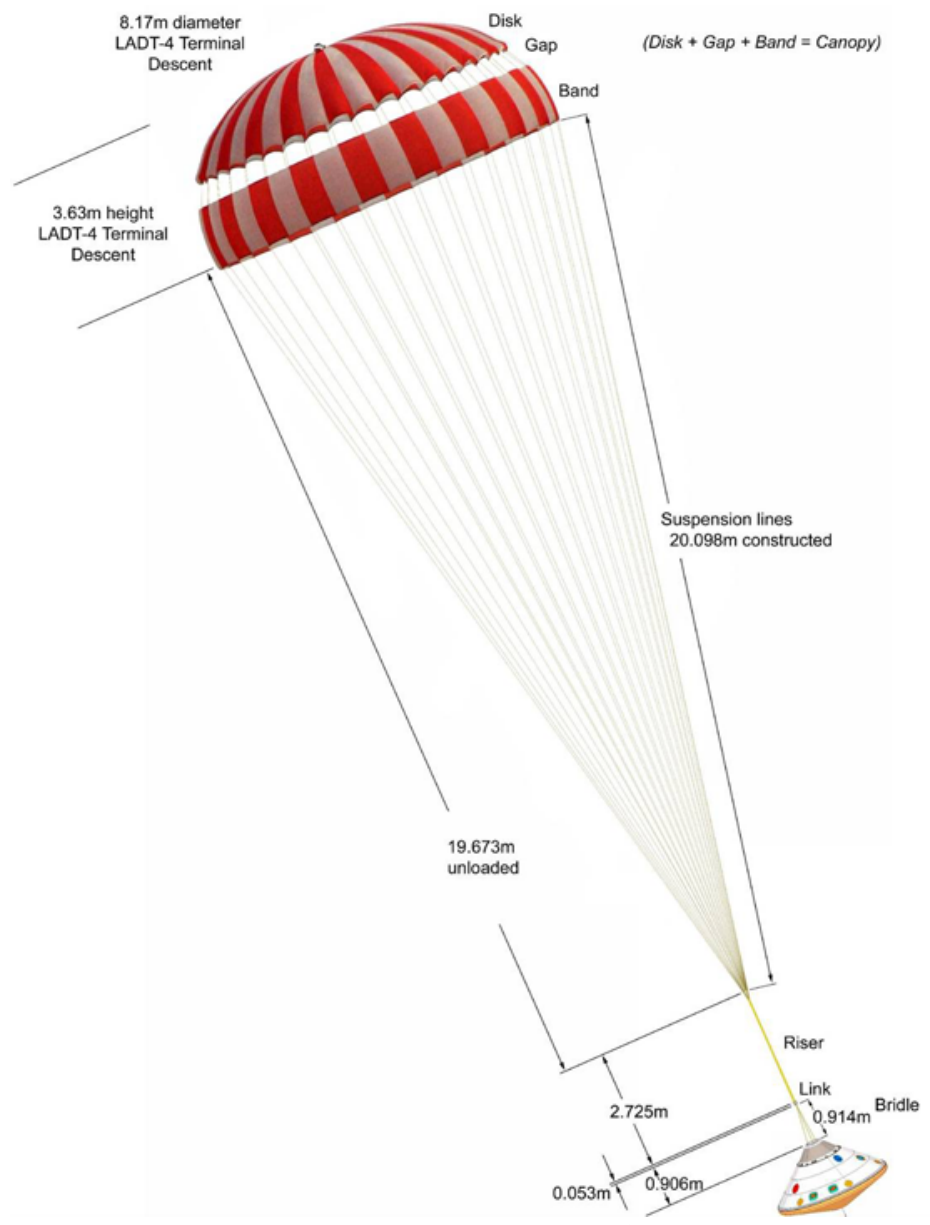

Figure 2. Phoenix parachute configuration.

\section{Parachute Description and Modeling}

The Phoenix parachute is a disk-gap-band parachute based on the Viking design. It is $11.73 \mathrm{~m}$ in nominal diameter. Note that the projected diameter of the parachute in flight (as shown in Fig. 2) differs from the nominal parachute diameter. The aerodynamics of the parachute are represented as coefficients of normal and axial force and pitching moment about the confluence point of the parachute suspension lines. The normal and axial force coefficients and the pitching moment coefficient vary with total angle of attack. The normal and axial force coefficients of the parachute are shown in Figs. 3 and 4 as a function of total angle of attack, and the pitching moment is shown in Fig. 5. In figures 3, 4 and 5, upper and lower bounds are shown. These bounds represent the upper and lower bounds used in the Monte Carlo analysis discussed below. The dispersions for these three quantities were correlated so that when the normal force was perturbed in a positive direction the axial force and pitching moment were perturbed in a negative direction and vice versa. 


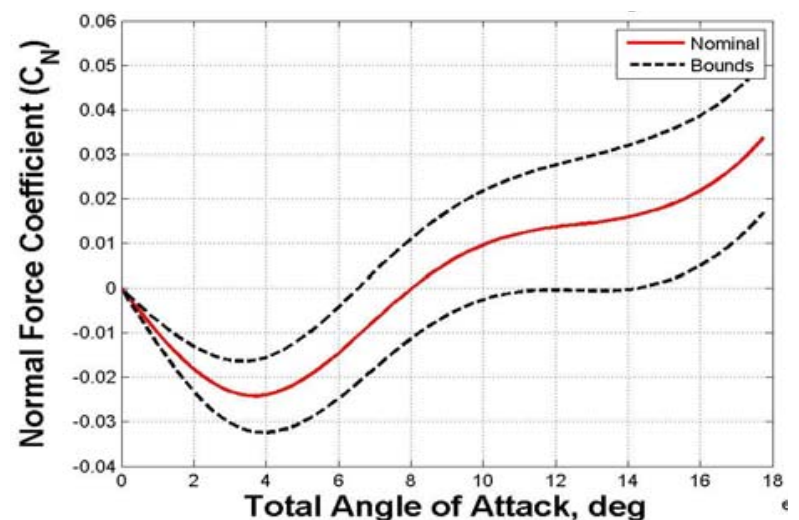

Figure 3. Phoenix parachute normal force coefficient.

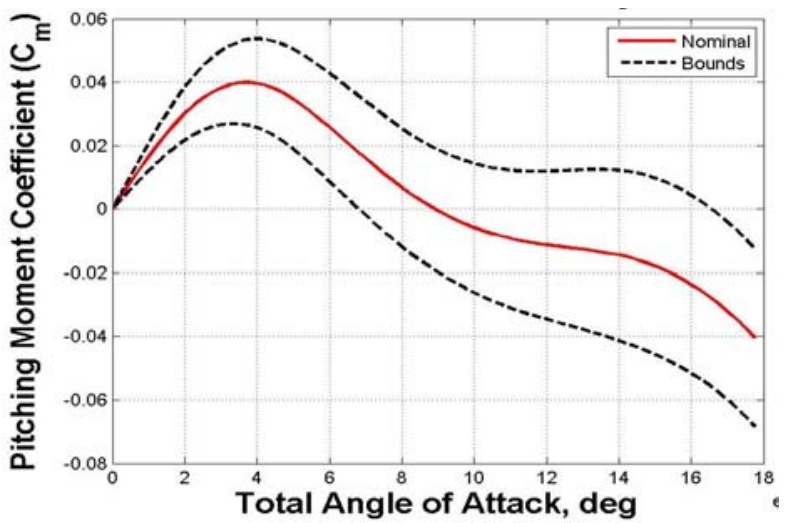

Figure 5. Phoenix parachute pitching moment coefficient.

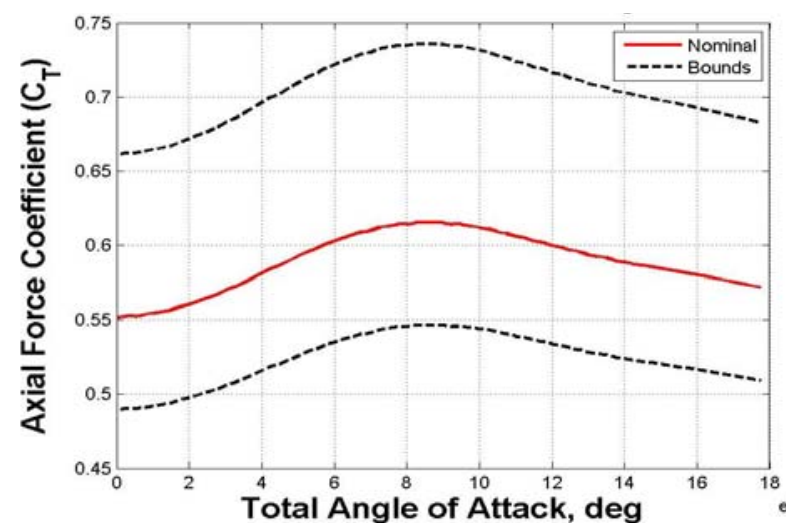

Figure 4. Phoenix parachute axial force coefficient.

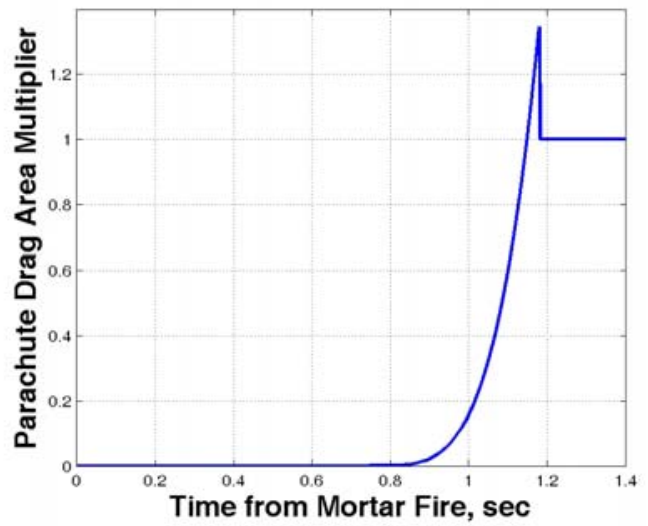

Figure 6. Phoenix parachute inflation profile.

Parachute inflation takes place over 1.2 seconds based on an inflation profile from Ref. 5 . The inflation profile is shown in Fig. 6. This inflation ratio is used as a multiplier on each of the aerodynamic coefficients for the parachute, from the time of mortar fire until full inflation. The axial force coefficient was modified according to the Mach (M) variation shown in Fig 7.

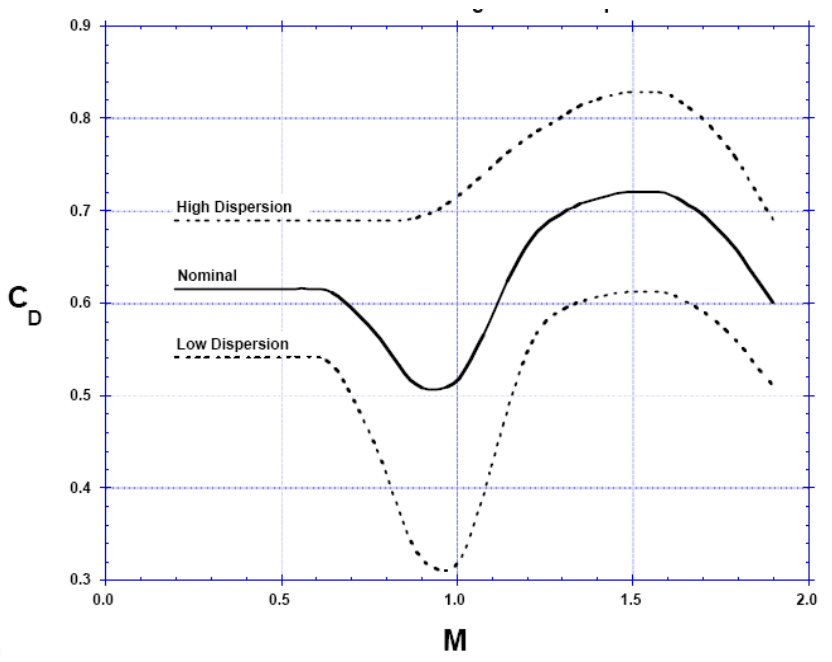

Figure 7. Phoenix parachute Drag variation with Mach Number. 


\section{Approach}

The underlying simulation software used for Phoenix is the Program to Optimize Simulated Trajectories II (POST II). POST II is the latest major upgrade to POST. ${ }^{6}$ POST was originally developed for the Space Shuttle program to optimize ascent and reentry trajectories. Over the years, it has been upgraded and improved to include many new capabilities. POST II relies on most of the technical elements established by POST, but the executive structure has been reworked to take advantage of today's faster computational capabilities. The new executive routines allow POST II to simulate multiple vehicles simultaneously, and to allow a combination of three degree of freedom (3DOF) vehicles with six degree of freedom (6DOF) vehicles within a single simulation. The multi-vehicle POST II capability was enhanced to allow interaction of forces and moments between the separate vehicles. As a result, parachutes interacting with other vehicles can be modeled allowing for a multi-body simulation capability. The lines connecting a vehicle and a parachute are modeled as massless spring-dampers. The springs can be attached at any point on the vehicle. No moments are applied except those due to force application away from the center of mass. Each line connects an attachment point on one vehicle to an attachment point on another vehicle and provides a tension-only force. When the lines are stretched, tension in the lines is determined as a function of strain and strain rate. Each of the spring-damper lines has an unstretched length and if the separation distance between the two attachment points is less than the unstretched length, the line tension is zero. Compressive damping forces are limited to be less than spring forces, so no line ever exerts a net compressive force.

For the results shown in this report, damping and stiffness were both assumed to be linear. For the single riser, both subsonic and supersonic, the stiffness used was $60,000 \mathrm{~N} / \mathrm{m}$, while for the triple bridle legs (each) the stiffness was $47,000 \mathrm{~N} / \mathrm{m}$. The damping in the riser was $600 \mathrm{~N} / \mathrm{m} / \mathrm{sec}$, while the damping in the triple bridle legs (each) was $470 \mathrm{~N} / \mathrm{m} / \mathrm{sec}$. The unstretched length of the riser was $2.778 \mathrm{~m}$, while that of the triple bridle legs (each) was $0.914 \mathrm{~m}$ (see Fig. 2). The triple risers were attached to a plate located $1.7305 \mathrm{~m}$ aft of the capsule nose. Each riser was located $0.119 \mathrm{~m}$ from the axis of symmetry of the capsule and the three bridle legs were located symmetrically, each clocked 120 deg from each other. The canopy and suspension lines were modeled as a single rigid body in order to alleviate the extreme numerical sensitivity, which was evident if the lines were modeled individually.

\section{Model Verification}

In order to verify the multi-body model as implemented in POST II, a series of increasingly complex test cases was performed. These test cases were intended to prove that the POST II model is implemented correctly by evaluating its performance on problems that could be verified by other means. The test cases started with a simple vertical drop from rest of the fully deployed parachute and capsule, and then gradually increased the simulation complexity to include parachute opening, lander deployment, retro-rocket firing, and other effects. The POST II model had been previously compared and validated to MATLAB-based and another multi-degree-of-freedom simulations ${ }^{8,9}$ In each case the agreement between the simulations was excellent. The verification work is reported in more detail in Refs. 8 and 9.

\section{Results}

After completion of the verification phase, the specific parachute configuration of the Phoenix Lander was incorporated into the simulation. The simulation was then used for a variety of analyses to characterize the overall performance of the Phoenix end-to-end entry, descent, and landing system. The response of Phoenix to a series of wind shears was investigated. The response at parachute deployment was simulated and compared to the response obtained using a simple "Wrist Mode" model of the parachute. The Wrist Mode model is a single-body model which treats the parachute as a pure drag device acting on the entry capsule. In addition, sensitivities to three different wind profile models were analyzed and the responses were assessed. Finally, the model was incorporated into a Monte Carlo simulation and the response was examined in a statistical sense.

\section{A. Wind Shear Response}

The behavior of the lander and parachute as they descend through a wind shear was examined. Figure 8 shows the wind profiles used in this test suite. For this test suite, the parachute and capsule were assumed to be initially falling straight down with a velocity of $60.6 \mathrm{~m} / \mathrm{s}$. Four cases were examined with wind shears beginning at 4, 3, 2 and $1 \mathrm{~km}$ above ground level. The vertical angle response of the capsule is shown in Fig. 9 and the lateral rotation rate is shown in Fig. 10. It is clear from the angle and rate responses that the capsule is well damped for this type of excitation. In Fig. 9, it can be seen that after an initial transient attitude excursion of approximately 30 deg, the capsule settles to less than 10 deg within about $250 \mathrm{~m}$. Similarly, Fig. 10 shows that transient rates of approximately $40 \mathrm{deg} / \mathrm{sec}$ damp to less than $10 \mathrm{deg} / \mathrm{sec}$ within $250 \mathrm{~m}$.

\section{6}

American Institute of Aeronautics and Astronautics 092407 


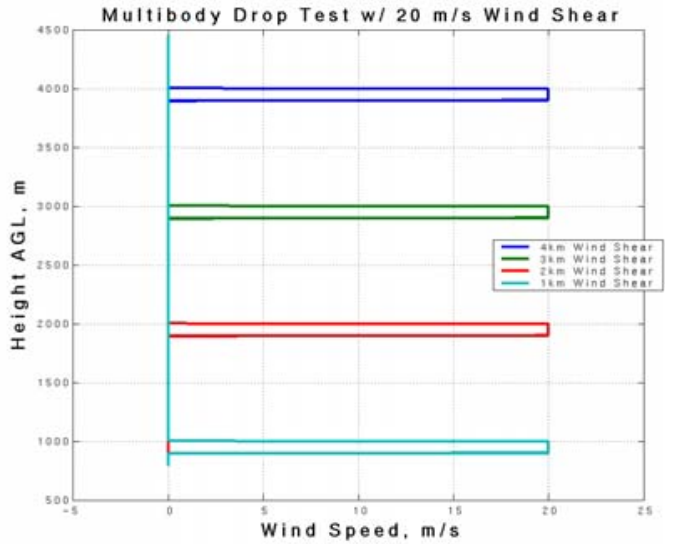

Figure 8. Wind shear profiles.

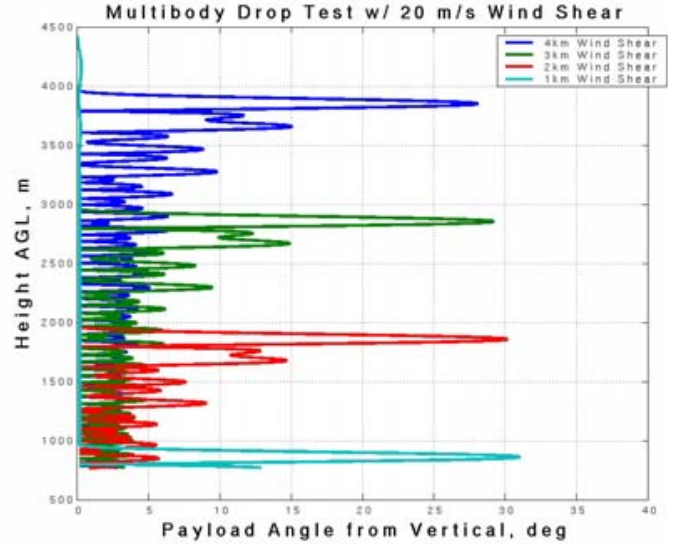

Figure 9. Capsule angular response to wind shear.

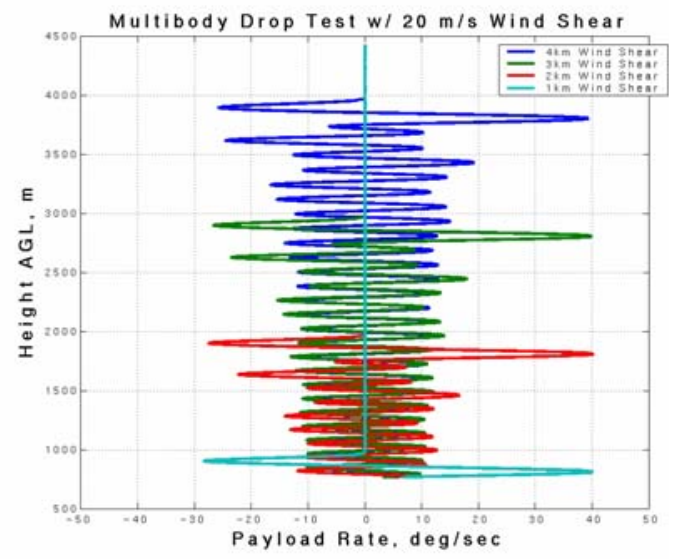

Figure 10. Capsule lateral rotation rate response to wind shear.

\section{B. Parachute Deployment and Inflation}

Since the opening of the parachute is a critical event, it was of particular interest. A set of simulations was performed to determine the vehicle response if the parachute took longer than expected to deploy and inflate or if the parachute "breathed" as it initially inflated. This "breathing" was modeled as a sinusoidal variation of the parachute drag coefficient about the nominal coefficient.These simulations included the nominal PEDLAM wind profile discussed below. The delayed opening case was modeled by stretching the inflation profile from Fig. 5 by a factor of five. Instead of opening in just over a second, the delayed opening took nearly 6 seconds. Figure 11 shows the drag force on the parachute for the cases considered. The delayed opening case lowered the opening loads slightly while the breathing cases raised the maximum drag force from approximately $47 \mathrm{kN}$ to $48 \mathrm{kN}$. As a result, the capsule body rates are excited by the opening event, but they damp out very quickly as seen in Fig. 12. 


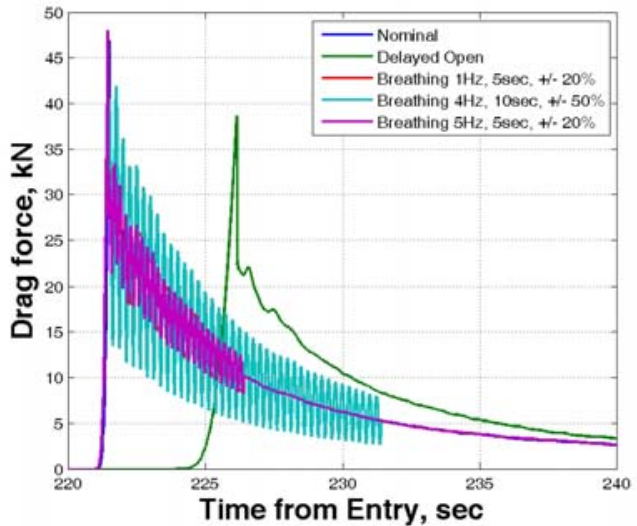

Figure 11. Parachute opening drag force.

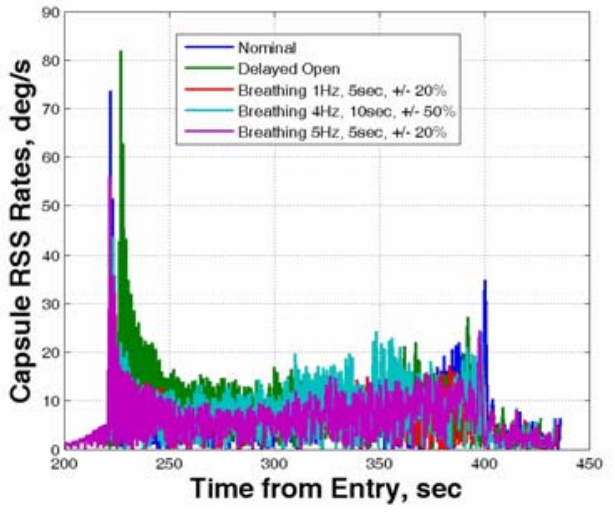

Figure 12. Capsule rates after parachute deploy.

Figure 13 shows the capsule total angle of attack from the time of parachute deploy to the ground. None of the off-nominal parachute openings had a significant effect on the angle of attack history. The attitude remains small (less than $30 \mathrm{deg}$ ) until lander separation at approximately $420 \mathrm{sec}$ when the tip-up maneuver is initiated increasing the total angle of attack to $~ 65$ deg prior to the start of the gravity turn for landing. The altitude-velocity histories of these five cases are shown in Fig. 14. Immediately following parachute deploy, the delayed opening case, in particular, diverges from the nominal, but by about $9 \mathrm{~km}$ above ground level (AGL), all of the trajectories are essentially nominal, and all cases performed successful landings.

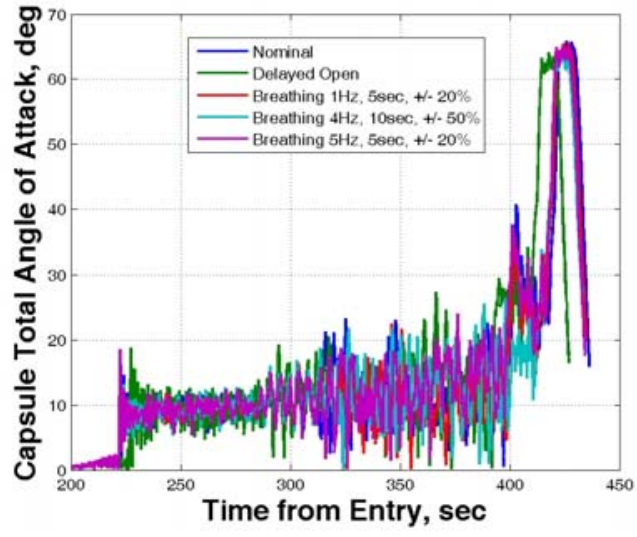

Figure 13. Capsule total angle of attack after parachute deploy.

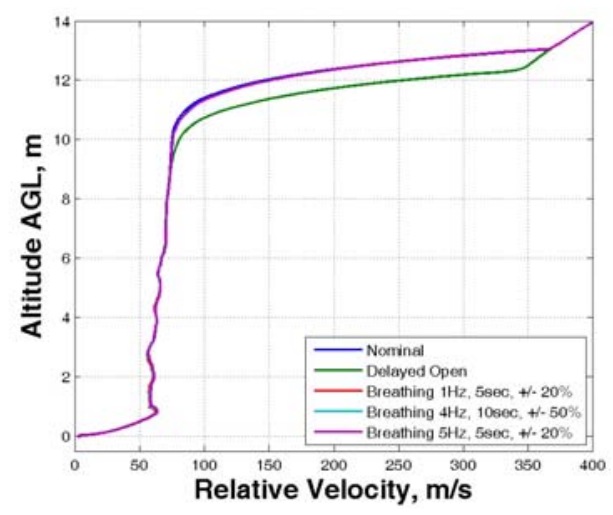

Figure 14. Altitude-velocity histories for offnominal parachute deployment.

\section{Wind Models}

Because the winds have such an impact on the behavior of the system while on the parachute, several wind models were investigated beyond the artificial wind shears described above. For Phoenix, three wind models were developed and examined: the Large Eddy Simulation (LES) wind model, the Turbulent Kinetic Energy (TKE) wind model and the Phoenix EDL Atmospheric Model (PEDLAM) wind model. The nominal north and east wind profiles for each of these models is shown in Fig. 15. It is apparent from Fig. 15 that the PEDLAM wind model has more high frequency content than the other two profiles. This model was the most stressful wind profile considered and was adopted as the reference for all subsequent analyses for conservatism.

The total angle of attack for the capsule is shown versus time in Fig. 16. It is clear from Fig. 16 that the PEDLAM wind model has the most impact on the attitude of the capsule (again the tip-up maneuver is observed at $\sim 420 \mathrm{sec}$ ). However, the LES winds result in a largest angle of attack at touchdown. Note that the parachute trims near 10 deg total angle of attack. Since the aerodynamics of the parachute dominates the capsule/parachute combination, the parachute attitude is reflected in the trim attitude of the capsule as well. 

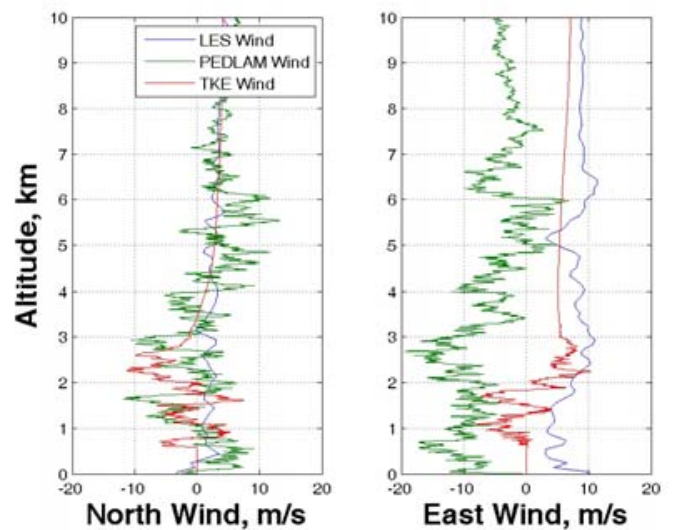

Figure 15. Nominal wind model profiles.

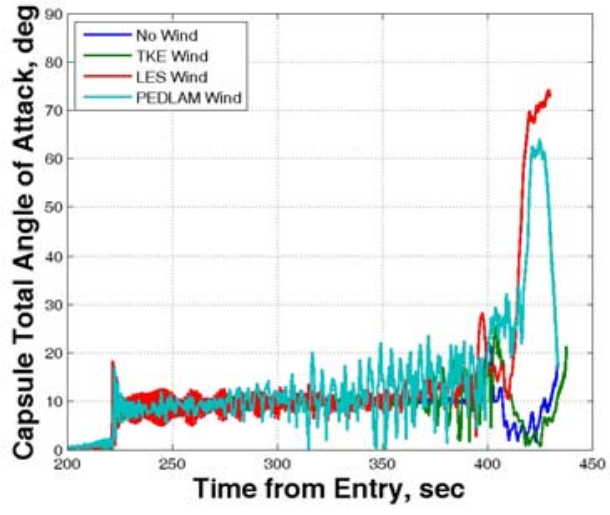

Figure 16. Capsule total angle of attack for various wind profiles

Figures 17 and 18 show the pitch angle responses of the capsule and parachute respectively for each of the wind profiles. Comparison of Figs. 17 and Fig 18 shows that the parachute is much less susceptible to high frequency motion than the capsule beneath it, and that the PEDLAM wind excites both capsule and parachute more than the other winds. In each of the wind cases considered in this analysis, the vehicle landed well within requirements. Table 1 summarizes some of the relevant touchdown statistics from these wind profile sensitivities. The vertical touchdown velocity requirement is greater than $1.4 \mathrm{~m} / \mathrm{s}$ and less than $3 \mathrm{~m} / \mathrm{s}$. The horizontal touchdown velocity limit is less than $1 \mathrm{~m} / \mathrm{s}$. It is clear that the vehicle makes a safe landing for each of the wind options. The TKE winds excited the largest attitude dispersions on the parachute while the LES winds excited the largest rates.

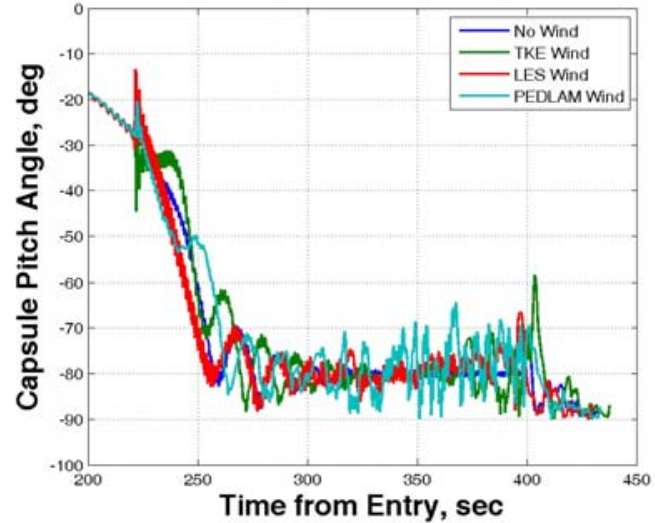

Figure 17. Capsule pitch angle wind comparison.

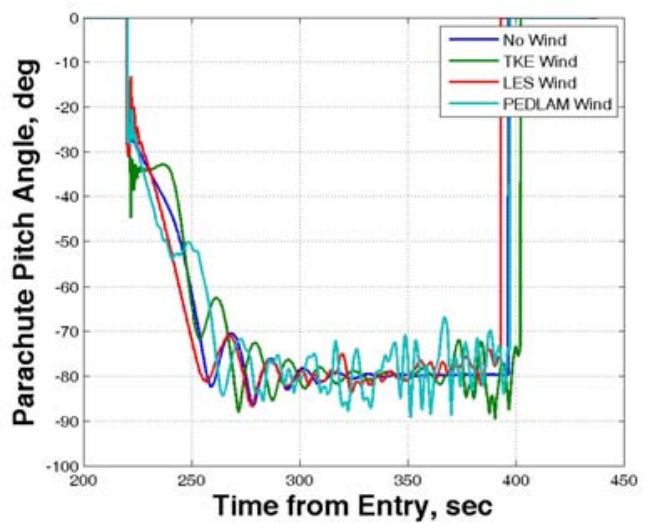

Figure 18. Parachute pitch angle wind comparison.

Table 1. Wind Comparison Statistics

\begin{tabular}{|l|c|c|c|c|}
\hline & \multicolumn{5}{|c|}{ Wind } \\
\hline Quantity & None & TKE & LES & PEDLAM \\
\hline Final Velocity (m/s) & 2.611 & 2.837 & 2.515 & 2.802 \\
\hline Final Horizontal Velocity (m/s) & 0.584 & 0.504 & 0.795 & 0.369 \\
\hline Final Vertical Velocity (m/s) & 2.545 & 2.792 & 2.385 & 2.778 \\
\hline Max Attitude from Nadir on Parachute (deg) & 17.072 & 28.890 & 17.222 & 22.751 \\
\hline Max Rate on Parachute (deg/s) & 77.461 & 77.855 & 93.703 & 50.713 \\
\hline Max Rate after Heatshield Separation (deg/s) & 20.481 & 24.703 & 30.833 & 27.595 \\
\hline Rate at Lander separation (deg/s) & 7.129 & 4.682 & 3.260 & 6.071 \\
\hline
\end{tabular}




\section{Monte Carlo Simulation}

The parachute model was incorporated into a Monte Carlo simulation. The Monte Carlo simulation was very similar to the single-body analysis described in Ref. 3. The input dispersions were the same as those in Ref. 3, except for the inclusion of the multi-body dispersions (e.g., parachute aerodynamic data, line properties, etc.) described previously in Sections II through IV, along with the specific inputs shown in Table 2.

Table 2. Monte Carlo Inputs

\begin{tabular}{|l|c|c|c|c|}
\hline Variable & Distribution & Units & Mean & 3 Sigma/Limits \\
\hline Line Stiffness Multiplier & Normal & - & 1.0 & 0.1 \\
\hline Line Damping Multiplier & Normal & - & 1.0 & 0.1 \\
\hline Entrained Air Volume & Uniform & $\mathrm{m}^{3}$ & 602.203 & \pm 403.145 \\
\hline Parachute Ixx, Iyy, Izz multiplier & Normal & - & 1.0 & 0.3 \\
\hline Parachute Ixy, Iyz, Ixz values & Normal & $\mathrm{Kg}^{*} \mathrm{~m}^{2}$ & 1.0 & 30 \\
\hline Parachute Inflation Rate multiplier & Normal & - & 1.0 & 0.1 \\
\hline Mortar Velocity & Normal & $\mathrm{m} / \mathrm{s}$ & 35.65 & 6.75 \\
\hline Mortar Pitch Relative to Capsule & Normal & $\mathrm{deg}$ & 0.0 & 2.5 \\
\hline Mortar Pitch to Parachute & Normal & $\mathrm{deg}$ & 180 & 2.5 \\
\hline Mortar Yaw & Normal & $\mathrm{deg}$ & 0 & 2.5 \\
\hline
\end{tabular}

Some selected relevant statistics from the multi-body Monte Carlo simulation are shown in Table 3. It is apparent from Table 3 that relatively small angles of attack at parachute deploy $(<10 \mathrm{deg})$ led to fairly high rates through heatshield separation (>100 deg/s). However, these high rates damped out very quickly. By the time of heatshield separation, the $99 \%$ high rates were less than $50 \mathrm{deg} / \mathrm{s}$ and by lander separation, the $99 \%$ high rates had reduced to less than $35 \mathrm{deg} / \mathrm{s}$. These results showed that the multi-body parachute system reliably damps out rotational motion of the capsule. This rotational damping was of intense interest to the project because of the sensitivity of the radar to angular rates greater than $100 \mathrm{deg} / \mathrm{s}$. This Monte Carlo resulted in 0.3 percent of cases violating constraints. The reasons for these violations were: horizontal velocity at touchdown too high (3 cases out of 2000), angle of attack too large at parachute deploy (2 cases out of 2000), and dynamic pressure too high at parachute deploy (1 case out of 2000). This was considered an acceptable risk to the project because of conservatism built into the simulation. This multi-body simulation provided sufficient confidence in the descent parachute/lander system dynamics to alleviate concerns of radar sensitivity or performance. The Phoenix Lander successfully landed on Mars on May 25, 2008. Details of the Phoenix EDL reconstruction and actual performance can be found in Ref. 10.

Table 3. Monte Carlo Output Statistics

\begin{tabular}{|c|c|c|c|c|}
\hline Parameter & Units & 99\% Low & Mean & 99\% High \\
\hline Max Total AoA from Chute Deploy to Heatshield sep & deg & 8.797 & 15.870 & 26.195 \\
\hline Max Pitch Rate from Chute Deploy to Heatshield sep & $\mathrm{deg} / \mathrm{s}$ & 8.169 & 44.944 & 121.621 \\
\hline Max Yaw Rate from Chute Deploy to Heatshield sep & $\mathrm{deg} / \mathrm{s}$ & 8.620 & 38.513 & 105.168 \\
\hline Total AoA at Chute Deploy & deg & 0.251 & 2.348 & 7.656 \\
\hline Total AoA at Heatshield sep & deg & 0.808 & 7.881 & 19.969 \\
\hline Total AoA at Lander sep & deg & 1.433 & 11.681 & 24.335 \\
\hline Pitch Angle at Lander sep & deg & -88.367 & -77.58 & -62.69 \\
\hline RSS Pitch Yaw rate at Chute Deploy & $\mathrm{deg} / \mathrm{s}$ & 0.337 & 4.349 & 15.165 \\
\hline RSS Pitch Yaw rate at Heatshield sep & $\mathrm{deg} / \mathrm{s}$ & 1.463 & 15.267 & 47.916 \\
\hline RSS Pitch Yaw rate at Lander sep & $\mathrm{deg} / \mathrm{s}$ & 1.426 & 11.741 & 33.038 \\
\hline
\end{tabular}

\section{Conclusion}

A multiple rigid-body parachute simulation model for the Phoenix entry, descent, and landing has been developed. The model includes dynamics caused by interacting lines and has been incorporated into an end-to-end 
simulation of the entry, descent and landing. This approach produced a higher fidelity simulation, especially with regard to capsule attitudes and rates while on the parachute. The capsule attitude and attitude rate were of particular interest to the mission team because of the sensitivity of the radar to large off-nadir angles and to large angular rates. It was seen that Phoenix was robust to wind shears of $20 \mathrm{~m} / \mathrm{s}$ while descending on the parachute. It was also seen that several off-nominal parachute openings could be accommodated by the system. In particular, when the parachute opening was drawn out by a factor of five and when an oscillatory opening (breathing) was enforced, the system continued on to a safe landing. Several wind models were investigated. The PEDLAM wind model was the most stressful to the system, but it was not so stressful as to prevent safe landing. Finally, the model was used in a Monte Carlo simulation which showed that even very high rates soon after parachute deployment were quickly damped down to acceptable levels.

\section{Acknowledgments}

The authors would like to thank Dr. Juan Cruz for providing much of the aerodynamic data used in this study and for his many constructive comments.

\section{References}

${ }^{1}$ Talay, T.A., "Parachute-Deployment-Parameter Identification Based on an Analytical Simulation of Viking BLDT AV-4", NASA TN D-7678, Aug. 1974.

${ }^{2}$ Grover, M. R., Cichy, B. D., and Desai, P. N., “Overview of the Phoenix Entry, Descent, and Landing System Architecture,” AIAA Paper 2008-7218, Proceedings of AIAA Guidance, Navigation, and Control Conference bit, Honolulu, HI, August 2008.

${ }^{3}$ Prince, J. L., Desai, P. N., Queen, E. M., and Grover, M. R., “Mars Phoenix Lander Entry, Descent, and Landing Simulation Design and Modeling Analysis,” AIAA Paper 2008-7346, Proceedings of AIAA Guidance, Navigation, and Control Conference, Honolulu, HI, August 2008.

${ }^{4}$ Cruz, J. R., Mineck, R. E., Keller, D. F., and Bobskill, M. V.: Wind Tunnel Testing of Various Disk-Gap-Band Parachutes, AIAA Paper 2003-2129, 2003.

${ }^{5}$ Ewing, E.G., Bixby, H. W. Knacke, T W., Recovery Systems Design Guide, AFFDL-TR-78-151, Dec. 1978.

${ }^{6}$ Powell, R.W., Striepe, S.A., Desai, P.N., Tartabini, P.V., Queen, E.M., Brauer, G.L., Cornick, D.E., Olson, D.W., Petersen, F.M., Stevenson, R., Engel, M.C., Marsh, S.M., Program to Optimize Simulated Trajectories: Volume II, Utilization Manual. Version 1.1.1.G, May 2000.

${ }^{7}$ Carman, G., Ives, D., and Geller, D., “Apollo-Derived Mars Precision Lander Guidance”, AIAA Paper 98-4570, AIAA Atmospheric Flight Mechanics Conference, Boston, Ma, Aug. 10-12, 1998.

${ }^{8}$ Calhoun, P., and Queen, E., “An Entry Vehicle Control System Design for the Mars Smart Lander”, AIAA Atmospheric Flight Mechanics Conference, AIAA paper 2002-4504, Aug. 5-8, 2002.

${ }^{9}$ Raiszadeh, B., and Queen, E., "Partial Validation of Multibody Parachute model in POST II", NASA TM-2002-211634, Oct. 2001.

${ }^{10}$ Desai, P. N., Prince, J. L., Queen, E. M., Cruz, J. R., and Grover, M. R., "Entry, Descent, and Landing Performance of the Mars Phoenix Lander”, AIAA-2008-7346, Proceedings of AIAA Guidance, Navigation, and Control Conference, Honolulu, HI, August 2008. 